\title{
Para uma Educação Sexual Corporizada: análise situada na educação básica em Portugal
}

\author{
For an Embodied Sexual Education: analysis located in basic \\ education in Portugal
}

\author{
Maria João Silva \\ Escola Superior de Educação/ Instituto Politécnico do Porto - Portugal \\ mjosilva@ese.ipp.pt \\ Maria da Luz Carvalho \\ Escola Superior de Educação/ Instituto Politécnico do Porto - Portugal \\ luz.carvalho.prof@gmail.com
}

\section{Resumo}

No presente artigo, cujo contexto é a educação sexual em Portugal, equaciona-se a importância e relevância da implementação de uma educação sexual corporizada. Analisa-se a evolução do currículo português de educação sexual, nomeadamente no que se refere a paradigmas, discursos e práticas. Procede-se a uma análise do papel do corpo no atual currículo de educação sexual, focando a atenção nas seguintes questões: O currículo português de educação básica integra uma abordagem corporizada à educação sexual? Como poderá a abordagem ao corpo ser holística, inclusiva e situada nos espaços quotidianos das crianças e jovens na educação básica? Apresenta-se um estudo de caso ilustrativo de educação sexual corporizada.

Palavras-Chave: Educação sexual; Abordagem Corporizada; Inclusão; Espaços quotidianos.

\begin{abstract}
In this paper, centered in Portuguese sex education, the importance and relevance of the implementation of an embodied sex education is discussed. The evolution of the sex education curriculum is analysed, particularly in what concerns paradigms, discourses and practices. The work presented in this paper analyses how bodies are addressed in the current sex education curriculum, focusing on the following questions: Does the elementary schools curriculum include an embodied approach to sex education in Portugal? How can human bodies be approached in a holistic and inclusive way, which is also situated in elementary school children's everyday spaces? A case study is presented to illustrate an embodied approach to sex education.
\end{abstract}

Keywords: Sex education; Embodied Approach; Inclusion; Everyday Spaces. 
Neste artigo, apresenta-se uma reflexão sobre a educação sexual corporizada, centrada na educação básica em Portugal. Para tal, equacionar-se-á e ilustrar-se-á, no referido âmbito, a importância, relevância e potencialidades da educação sexual corporizada.

Neste contexto, adopta-se o conceito definido pela Organização Mundial de Saúde, considerando a sexualidade como um aspecto central do ser humano, que acompanha toda a vida e que inclui o sexo, a identidade, os papéis de género, a orientação sexual, o erotismo, o prazer, a intimidade e a reprodução (WHO, 2006). Segundo esta definição, a sexualidade é vivida e expressa em pensamentos, fantasias, desejos, crenças, atitudes, valores, comportamentos, práticas, papéis e relações, sendo influenciada pela interacção de factores biológicos, psicológicos, sociais, económicos, políticos, culturais, éticos, legais, históricos, religiosos e espirituais (WHO, 2006).

No mesmo sentido, e também segundo a Organização Mundial de Saúde, considera-se que a educação sexual visa à promoção da saúde, do bem-estar e dos direitos sexuais (WHO, 2006). Encara-se a educação sexual como um direito sexual, em conjunto com outros direitos, como por exemplo, o de escolha do/a parceiro/a e o de procurar uma vida sexual satisfatória, segura e prazerosa (WHO, 2006).

Tendo como base as anteriores definições, torna-se claro que, embora a educação ocidental raramente o foque abertamente, nomeadamente na escola (ANSELL, 2009), o corpo é central e incontornável em educação sexual. Segundo Nicola Ansell (2009), por influência do dualismo cartesiano, a escola tem dado supremacia à razão e relegado o corpo para um estatuto inferior e só recentemente a educação e a geografia têm vindo a reconhecer o significado da não falada presença dos corpos nas escolas.
Neste artigo, perspetiva-se uma educação sexual que inclua uma abordagem holística e inclusiva ao corpo e às suas emoções. Para tal, considera-se a sala de aula como espaço quotidiano, onde as crianças e jovens também constroem e dão sentidos aos corpos.

Nas secções seguintes, apresenta-se uma análise à educação sexual em Portugal, questionando a existência de um lugar no currículo para uma abordagem corporizada. Em sequência, analisa-se a possibilidade e exigências de uma abordagem ao corpo e suas emoções, que seja holística, situada e inclusiva. Antes das conclusões, termina-se com um estudo de caso, ilustrativo da abordagem preconizada.

\section{Educação Sexual em Portugal: Paradigmas e Modelos}

Frade et al. (2001) realçam que, no que se refere à implementação da educação sexual em Portugal, foram necessários 25 anos para progredir "de uma mera intenção legislativa (LEI 3/84) para um quadro legal e normativo" (p. 21), que inclui objetivos, tópicos e orientações metodológicas (LEI 60/2009).

A Lei $n^{\circ} 3$ de 1984 criou, através do Ministério da Saúde, centros de atendimento gratuitos para jovens e estabeleceu que a educação sexual era um direito garantido pelo Estado, definindo que os currículos do ensino básico e secundário deviam incluir conhecimento científico sobre anatomia, fisiologia, genética e sexualidade humana, salientando, ainda, a necessidade de o Ministério da Educação desenvolver a formação inicial e contínua de docentes em educação sexual (CIBELE, BARROSO e CARVALHO, 2010).

Os mesmos autores realçam que quinze anos mais tarde, a Lei $\mathrm{n}^{\circ} 120$ de 1999 repetiu as mesmas obrigações para os dois ministérios. No entanto, esta Lei introduziu 
pela primeira vez a questão da igualdade entre os sexos, enfatizou a necessidade de compreensão das doenças sexualmente transmissíveis e estabeleceu que as escolas secundárias deveriam considerar a distribuição gratuita de preservativos (CIBELE, BARROSO e CARVALHO, 2010). As duas leis atrás referidas enquadram-se no paradigma biomédico ou médico-preventivo ou ainda modelo de educação sexual como forma de evitar riscos (SERRÃO, 2009). A Lei 3/84 alia a educação sexual ao planeamento familiar, tentando fazer face ao problema das gravidezes indesejadas, nomeadamente na adolescência, enquanto a Lei 120/99 inclui esta dimensão e associa a educação sexual à necessidade de conter a epidemia SIDA (CIBELE, BARROSO e CARVALHO, 2010).

Segundo aqueles autores, a Lei 60/2009 inicia uma abordagem à sexualidade humana que se enquadra no paradigma psicossociológico, ou modelo de educação sexual biopsicossocial, ou ainda modelo de desenvolvimento pessoal e social (SERRÃO, 2009). Trata-se de um modelo de promoção da saúde Centrado no Utente. Neste contexto, a Lei 60/2009 valoriza a sexualidade e a afetividade entre as pessoas, respeitando a sociedade plural portuguesa e incluindo a consideração da educação sexual como um meio para prevenir a discriminação baseada na orientação sexual, a violência, a exploração e os abusos sexuais, sem, no entanto se centrar na luta pelos direitos e contra as discriminações, não podendo, por isso, ser considerada como integrada no modelo sociopolítico (CIBELE, BARROSO e CARVALHO, 2010), nem no modelo para a alteração social (EWLES e SIMNETT, 1999).

\section{A abordagem corporizada tem lugar no currículo português de educação sexual?}

Com pequenas exceções, por exemplo, em educação física, no currículo português de educação básica e nas escolas portuguesas, observa-se o que Colls e Hörschelmann (2009) equacionam num outro contexto:

Apesar de um movimento explícito na política para se educar através do corpo, desenvolvendo uma abordagem para as 'competências de vida', que tem em consideração os elementos interpessoais e psicossociais de subjetividade, presentemente o currículo reproduz um corpo aprendente normativo propenso ao controlo e proteção e à aprendizagem cognitiva e não corporizada (p. 4).

O corpo é uma construção e realidade vivida socialmente, é um espaço de subjetividade, sujeito a saberes organizados e normativos, pelo que qualquer conceção educativa deve privilegiar o conhecimento e a experimentação do corpo (PINTO et al., 2010). No entanto, na escola, o corpo tem sido ignorado e, essencialmente controlado.

Não é fácil encontrar um lugar para a educação sexual corporizada no currículo português de educação sexual (estabelecido pela Lei 60/2009 e pela Portaria 196A/2010), considerando a ausência dos seguintes tópicos:

- Diversidade dos corpos e de práticas corporizadas nos espaços quotidianos;

- Sexualidades em que os corpos e seus comportamentos são resultado de fatores históricos, sociais e políticos.

A Lei 60/2009 e a Portaria 196A/2010 que a regulamenta, abordam o corpo humano de forma limitada, integrando nomeadamente os seguintes tópicos:

- Conhecimento científico da reprodução 
humana;

- Prevenção em relação a gravidezes indesejadas, infeções sexualmente transmissíveis, violência e outros riscos;

- Desenvolvimento de uma sexualidade saudável e gratificante, sem, no entanto fazer referência específica aos corpos.

Anastácio, Carvalho, e Clément (2007) concluem que os/as professores/as do $1^{\circ}$ ciclo do ensino básico em Portugal têm mais dificuldade em trabalhar tópicos relacionados com o prazer e que se sentem mais seguros a trabalhar as questões relacionadas com a afetividade. Constatando a existência deste 'golfo' entre afetividade e prazer, parece clara a necessidade de apoiar os/as docentes no desenvolvimento de abordagens corporizadas em educação sexual.

Os recursos disponibilizados pelo Ministério da Educação para apoiar os professores nas suas intervenções educativas de educação sexual são escassos. A Lei 60/2009, define os objetivos da educação sexual, os tópicos e um conjunto de orientações metodológicas muito gerais. A Portaria 196A/2010, define os conteúdos mínimos para cada ciclo de escolaridade.

O Ministério não disponibilizou outras orientações ou recursos didáticos. No entanto, nomeou um grupo de peritos para avaliar um conjunto de recursos didáticos, na sua maioria livros. A avaliação realizada não oferece informação que possa apoiar os/as professores/as de forma significativa, uma vez que os resultados da avaliação são similares para quase todos os recursos e quase não foram produzidos comentários descritivos sobre os recursos.

Alguns dos recursos positivamente avaliados, pelo grupo de peritos nomeado pelo Ministério da Educação, integram uma abordagem corporizada da educação sexual. Realçam-se dois exemplos:
1. Os recursos produzidos pela Associação para o Planejamento da Família incluem a abordagem preconizada Ansell (2009): para além da disponibilização de informação sobre os corpos, recomendam o recurso aos corpos para melhorar as competências comunicacionais, de tomada de decisão, de reflexão, de relação interpessoal e de gestão de emoções. Ou seja, enfatizam a importância da linguagem corporal e recomendam a utilização do corpo no processo de ensino/aprendizagem, ligando a afetividade ao prazer e à saúde (ANSELL, 2009).

2. O livro "Vamos falar de sexo", escrito por Robie Harris, merece atenção por um conjunto diversificado de razões:

- Inclui representações múltiplas da diversidade e da inclusão quando apresenta os corpos (idades, etnias, deficiência, etc.), as famílias, as emoções, as relações, os comportamentos, a igualdade, etc.

- Os corpos de crianças, jovens, homens e mulheres, são explicitamente apresentados. Também é explicado que os genitais femininos apenas são auto-observáveis com o recurso a um espelho. Ainda hoje, muitos manuais não representam as componentes da vulva e, por vezes, até as análises académicas aos manuais (por exemplo, DIOGO, 2011) não identificam este problema, invisibilizando a invisibilidade.

- Não existe um capítulo específico para falar de homossexualidade. Visibiliza a homossexualidade quando discute diversos tópicos, como o desejo, os comportamentos sexuais, as famílias, as relações e o género, em atividades e espaços do quotidiano.

- Pode assim afirmar-se que, não sendo fácil encontrar um lugar para a educação sexual corporizada no currículo português de educação sexual, o Ministério da Educação validou um conjunto de recursos onde se podem encontrar apoios pedagógicos para a implementação de uma abordagem 
corporizada.

\section{Para uma abordagem corporizada holística, inclusiva e situada nos espaços quotidianos das crianças e jovens}

Na sequência da análise do currículo de educação sexual em Portugal realizada na secção anterior, nesta secção equaciona-se como poderá uma abordagem corporizada à Educação Sexual ser holística, inclusiva e situada nos espaços quotidianos das crianças e jovens na Educação Básica. Analisar-se-ão as componentes de uma abordagem corporizada, com o corpo e pelo corpo, cognitiva, mas também sensorial e emocional e, por isso, situada nos espaços onde acontece.

O corpo é o foco de toda a experiência, da sensação e da emoção, mudando constantemente, principalmente na infância (ANSELL, 2009). Uma aprendizagem corporizada é sempre situada, não obstante as múltiplas tentativas dos sistemas culturais, científicos e educativos para retirar ou ocultar o corpo nos processos de conhecimento (IHDE, 2002). Para as crianças e jovens na educação básica, a casa, a escola e as relações entre estes dois espaços têm uma importância central para a forma como vivem e constroem os seus corpos (ANSELL, 2009; HARDEN, 2012; VALENTINE, 2003).

As escolas integram e formatam os corpos das crianças e jovens, através de práticas explícitas, nomeadamente do currículo (ANSELL, 2009). Na sala de aula de uma escola escocesa, onde foi desenvolvida a investigação reportada em Harden (2012), evidenciaram-se as restrições colocadas aos corpos das crianças nos seus movimentos e interações. Na Escócia, como em Portugal, na sala de aula, como nos recreios, as crianças constroem os seus corpos e espaços, de forma genderizada, transgredindo, mas também reforçando estereótipos e regulações sociais (HARDEN, 2012; LOPES, 2002; PEREIRA,
2009).

Para uma abordagem corporizada holística e inclusiva da sexualidade, é fundamental integrar e atender à complexidade das quatro componentes da identidade sexual: sexo biológico, identidade de género, papéis sexuais e orientação sexual (SHIVELY e DE CECCO, 1977). No contexto da educação sexual em Portugal, é possível encontrar recursos para apoio didático a intervenções sobre género ${ }^{1}$ e orientação sexual ${ }^{2}$. No entanto, não se encontram recursos que integrem as referidas quatro dimensões da identidade sexual, ou que trabalhem a intersexualidade, por exemplo. Falta ainda percorrer um longo caminho até à desconstrução dos estereótipos, até ao conhecimento e valorização da diversidade, até uma educação sexual que considere a construção dos corpos como social e política, integrando-se num modelo de desenvolvimento pessoal, mas também de alteração social.

As crianças vivem e constroem os seus corpos de formas diferentes em função das regulações sociais dos seus diversos espaços quotidianos (HARDEN, 2012). Na sala de aula, a dimensão cognitiva tem precedência sobre a emocional e a física, o corpo ainda não tem uma materialidade visceral, sendo visto mais como uma máquina ou um conjunto de diagramas num manual escolar (ANSELL, 2009). Para uma educação sexual corporizada inclusiva, é necessária uma integração holística dos corpos e da complexidade dos espaços que os constroem e que por eles são construídos, nomeadamente no que se refere ao papel da sexualidade, género, classe e etnia (VALENTINE, 2003).

Particularizando, Valentine (2003) realça que, para apoiar as crianças e jovens na compreensão ativa das transições entre os corpos infantis e os corpos adultos, é necessário dar voz às crianças e jovens, 
dando mais atenção às:

- Experiências corporizadas das crianças em diferentes espaços (como a casa e a escola) e nas relações entre esses espaços;

- Diversas definições e representações dos/as jovens sobre o cruzar das fronteiras entre os corpos infantis e os corpos adultos.

\section{Estudo de caso: Uma abordagem corporizada à prevenção da violência de género}

Nos últimos anos, a educação formal tem vindo a dar especial atenção à aprendizagem e desenvolvimento emocional das crianças (HARDEN, 2012). Segundo o mesmo autor, a escola é um local chave cujas práticas influenciam a forma como as crianças dão sentido aos seus corpos, sentimentos e emoções. É neste âmbito que apresentamos resumidamente um estudo de caso ilustrativo de uma abordagem corporizada à educação sexual, dando especial atenção à educação das emoções, nomeadamente à consciência das mesmas e à sua gestão.

Trata-se de um estudo de caso realizado no contexto de um projeto de mestrado (CARVALHO, 2011). Foi desenvolvido com uma turma de $6^{\circ}$ ano de escolaridade com o objetivo de contribuir para a prevenção da violência no namoro heterossexual entre adolescentes. Partiu-se do pressuposto que é desejável que, logo desde os primeiros namoros, os parceiros sejam capazes de detectar, em si, sinais físicos concomitantes a emoções como a exaltação e a zanga, para melhorar o auto-controlo.

Neste estudo, a recolha de dados centrouse na observação participante realizada pela professora-investigadora, nos documentos criados pelas/os alunas/os, nos registos áudio (todas as sessões) e vídeo (sesões de role-play e debate) e na utilização de um sensor de ritmo cardíaco ligado a um computador, que permitiu a construção automática de gráficos e tabelas em simultâneo com a recolha dos dados, tornando possível a análise dos dados em tempo real.

A investigação em Portugal comprova a inclinação por parte dos jovens para condenar a violência em contextos de intimidade ainda que, quando aprofundados os seus discursos, surjam posturas divergentes, tais como a banalização da violência emocional e de formas de violência sexual entendidas como menos graves, a desculpabilização do comportamento violento perante a ausência de intenção por parte do agressor, do arrependimento manifestado, do contexto privado da violência e da ausência de consequências físicas graves para a vítima, bem como a atribuição da causalidade da violência a factores que estão fora do controlo do agressor ou, inclusivamente, que são da responsabilidade da vítima (CARIDADE, 2008).

Neste contexto, debateu-se o fenómeno da violência, identificando-se causas, tipos, formas e consequências. As crianças identificaram os parâmetros que denunciam a vivência de uma relação 'não saudável' e abusiva.

Alguns mitos e crenças em torno da violência podem ser entendidos como formas estereotipadas de conceber o fenómeno, negando-o, normalizando-o ou justificando-o. Por este motivo, desmistificaram-se ideias erradas acerca da violência no namoro, nomeadamente no que diz respeito a forçar beijos e a explorar o corpo do/a namorado/a contra a vontade.

Dramatizaram-se e debateram-se casos específicos de violência no namoro. Numa das dramatizações, participaram três rapazes: um, que usou o sensor de ritmo cardíaco durante o role play representou o papel do namorado ciumento que não deixava a namorada ir ao cinema com os amigos ('porque eu quero, porque eu mando', 'eu mando em ti'); o outro interpretou o papel da 
namorada que não quis obedecer ('não me calo', 'e vou'), tendo em sequência sido agredida com um estalo; e o amigo que não teve intervenções orais, apenas assistiu à discussão.

$\mathrm{O}$ valor mais elevado adquirido pelo sensor foi de 250 batimentos cardíacos por minuto, quando o aluno agrediu a 'namorada', e um dos valores mais baixos (50 batimentos cardíacos por minuto) foi registado quando a 'namorada' se afastou.

No final dos role play, os/as alunos/as identificaram sentimentos, emoções e comportamentos que tinham antecedido as situações de violência. Quando questionados sobre o que fazer quando detetarem em si ou no outro estas emoções e/ou comportamentos afirmaram que 'é melhor conversar com calma' ou 'ir apanhar ar'. A capacidade de identificar emoções como exaltação e zanga em si mesmo e/ou em outras pessoas com quem se relaciona, desenvolver a capacidade de tolerar reacções emocionais desagradáveis, compreendê-las ou diminuir a sua importância, controlá-las ou descarregá-las no momento apropriado (BUENO e PRIMI, 2003) é essencial para evitar situações de violência.

Numa atividade seguinte, os alunos leram e interpretaram uma história e decidiram entre eles que papéis seriam atribuídos a cada um. Os 'amigos e familiares da vítima' utilizaram os dados do texto na sua argumentação. Os 'amigos e familiares do agressor' usaram a criatividade.

No final do debate, a professora investigadora perguntou aos amigos do agressor se na realidade o defenderiam com tanto afinco, sabendo que era culpado. Nesse momento, o ritmo cardíaco do aluno que representou o papel de namorado atingiu o valor mais elevado (240 batimentos por minuto). Foram atingidos outros picos, quando se sentiu ameaçado (o pai da namorada ameaçou matá-lo) e em vários momentos de discussão exaltada.

As dramatizações possibilitaram a reflexão corporizada sobre a complexidade de sentimentos, emoções e pensamentos relacionados com situações de violência de género no namoro adolescente heterossexual. A monitorização do ritmo cardíaco alertou para a identificação de sentimentos, emoções e comportamentos que antecedem situações de violência e motivou o equacionar de ações de prevenção de violência.

\section{Conclusão}

No presente artigo, cujo contexto é a educação sexual em Portugal, equacionou-se a importância e relevância da implementação de uma educação sexual corporizada.

No currículo da educação básica em Portugal, a educação sexual está integrada na educação para a saúde desde 2009, centrandose no modelo de educação sexual biopsicossocial, ou modelo de desenvolvimento pessoal e social. Embora compreenda a saúde sexual, reprodutiva e a prevenção da discriminação e da violência, visando uma sexualidade saudável e gratificante, o atual currículo de educação sexual não explicita uma abordagem corporizada. No entanto, o Ministério da Educação validou a qualidade de um conjunto de recursos educativos que apresentam estratégias diversificadas de implementação de uma educação sexual corporizada.

$\mathrm{Na}$ sequência dessa análise, neste artigo, considerou-se que para que uma abordagem corporizada à Educação Sexual seja holística, inclusiva e situada nos espaços quotidianos das crianças e jovens na Educação Básica, a Escola deve estudar os diversos espaços quotidianos e a forma como as crianças se relacionam com os mesmos e neles inscrevem e constroem os próprios corpos e suas transformações de crescimento, em interação com as regulações sociais. Neste contexto, 
explicitou-se também a importância de compreender e integrar diferentes dimensões da identidade sexual, nomeadamente o sexo biológico, a identidade de género, os papéis de género e a orientação sexual.

Apresentou-se um estudo de caso, ilustrativo de uma abordagem corporizada à violência de género, num contexto de educação sexual formal. Nesse estudo de caso, o corpo e as suas emoções tiveram lugar central e deram origem a vivências e reflexões relevantes para a prevenção da violência de género.

Conclui-se, perspetivando as tecnologias móveis como ferramentas que podem contribuir para a monitorização dos estados do corpo, facilitando abordagens corporizadas, holísticas e situadas em educação sexual.

1 Ver, por exemplo, Guiões de Educação, Género e Cidadania em http://www.cig.gov.pt/

2 Ver os materiais criados por ONG, como por exemplo, www.rea.pt/materiais-educativos/ e http://ilga-portugal.pt/educacao/

\section{Referências}

ANASTÁCIO, Zélia; CARVALHO, Graça S.; CLÉMENT, Pierre. Educação sexual no $1^{\circ} \mathrm{ceb}$ : Percepções dos professores sobre as suas dificuldades em áreas e tópicos específicos. In: LOPES, Bernardino; CRAVINO, José Paulo (Orgs.). Contributos para a qualidade educativa no ensino das ciências do pré-escolar ao superior: Actas do Encontro Nacional de Educação em Ciências, [CD-ROM]. Vila Real: Universidade de Trás-os-Montes e Alto Douro, 2007, p. 150 - 155.

Ansell, Nicola. Embodied learning: responding to AIDS in Lesotho's education sector. Children's Geographies, v. 7, n. 1, p.
$21-36,2009$.

BUENO, José Maurício Haas; PRIMI, Ricardo. Inteligência Emocional: Um Estudo de Validade sobre a Capacidade de Perceber Emoções". Psicologia: Reflexão e Crítica, v. 16, n. 2, p. 279 - 291, 2003.

CARIDADE, Sónia. Violência nas relações de intimidade: Comportamentos e atitudes dos jovens. 2009. Tese (Doutorado em Psicologia, área de conhecimento em Psicologia da Justiça) - Instituto de Educação e Psicologia da Universidade do Minho, Braga. 2009.

CARVALHO, Maria da Luz. Prevenção da Violência de Género no Namoro Heterossexual entre Adolescentes: Estudo de Caso com uma Turma do $6^{\circ}$ Ano do Ensino Básico. 2011. Relatório de Projeto (Mestrado em Ensino Experimental das Ciências no $1^{\circ}$ e $2^{\circ}$ Ciclos do Ensino Básico) - Escola Superior de Educação do Instituto Politécnico do Porto, Porto.

CIBELE, Carla; BARROSO, João; CARVALHO, Luís Miguel. Knowledge and public action: Sex education in school (1984-2009). Lisbon: University of Lisbon, Institute of Education, 2010. [com a colaboração de Carla Menitra]. KNOWANDPOL National Report.

COLLS, Rachel; HÖRSCHELMANN, Kathrin. The geographies of children's and young people's bodies". Children's Geographies, v. 7, n. 1, p. 1 - 6, 2009.

DIOGO, Anabela Salvado. A educação sexual veiculada pelos manuais escolares: um contributo para a prática docente no $1^{\circ}$ Ciclo. 2011. Tese (Doutorado em Ciências da Educação, Especialidade Didática) Universidade Aberta, Lisboa. 2011. 
EWLES, Linda; SIMNETT, Ina. Promoting health: a pratical guide. $4^{\mathrm{a}}$ edição. Edinburgh: Bailière Tindall, 1999.

HARDEN, Jeni. Good sitting, looking and listening: the regulation of young children's emotions in the classroom. Children's Geographies, v. 10, n. 1, p. 83 - 93, 2012.

IHDE, Don. Bodies in Technology. Minneapolis, London: University of Minnesota Press, 2002.

Lei $N^{\circ} 120 / 99$, de 11 de agosto, Diário da República, I Série - A.

Lei $\mathrm{N}^{0}$ 60/2009, de 6 de agosto, Diário da República, I Série.

LOPES, João Teixeira. O Estranho Mundo da Escola Secundária Ferreira de Castro: Comportamentos de Género em Espaço Escolar". ex aequo, v. 7, p. 99-105, 2002.

PEREIRA, Maria do Mar. Fazendo género na escola: Uma análise performativa da negociação do género entre jovens. ex aequo, v. 20 , p. $113-127,2009$.

Pinto, Teresa; Nogueira, Conceição; Vieira, Cristina; Silva, Isabel; Saavedra, Luísa; Silva, Maria João; Silva, Paula; Tavares, TeresaCláudia; Prazeres, Vasco. Guião de Educação Género e Cidadania - $\mathbf{3}^{\mathbf{0}}$ ciclo do ensino básico. ISBN: 978-972-597-323-6. Lisboa: Comissão para a Cidadania e a Igualdade de Género, 2010.

Portaria No 196-A/2010 de 9 de abril, Diário da República, I Série-A.

SERRÃO, Carla. Práticas de Educação Sexual em contexto escolar: Factores preditores do envolvimento dos professores na promoção da educação sexual. 2009. Tese (Doutorado em Psicologia). Faculdade de Psicologia e de Ciências da Educação da
Universidade do Porto, Porto, 2009.

SHIVELY Michael; DE CECCO, John. Components of sexual identity. Journal of Homosexuality, v. 3, n. 1, p. 41 - 48, 1977.

VALENTINE, Gill. Boundary Crossings: Transitions from Childhood to Adulthood. Children's Geographies, v. 1, n. 1, 37 - 52, 2003

WHO (2006). Defining sexual health: Report of a technical consultation on sexual health. World Health Organization, Geneva, 28-31 January, 2002.

Recebido em 15 de dezembro de 2013. Aceito em 01 de fevereiro de 2014. 